\title{
Selecting the best statistical distribution with PROMETHEE and GAIA
}

\author{
Alessio Ishizaka ${ }^{* 1}$, Philippe Nemery ${ }^{2}$ \\ ${ }^{1}$ University of Portsmouth, Portsmouth Business School, Richmond Building, Portland \\ Street, PO1 3DE Portsmouth, United Kingdom, Alessio.Ishizaka@port.ac.uk \\ ${ }^{2}$ University of Portsmouth, Department of Mathematics, Lion Gate Building, Portsmouth \\ PO1 3HF, United Kingdom, pnemery@gmail.com
}

\begin{abstract}
Three methods have previously been presented in Computer and Industrial Engineering for the selection of a statistical distribution to describe a data-set: the weighted sum model, the weighted multiplication model and data envelopment analysis. These are based on distinctive preset of parameters and result in three different rankings. In these approaches there is no interaction with the decision-maker (DM). This leads to the question: which method should a DM choose? In this paper, we adopt another approach where the DM is the central actor. Based on the multi-criteria decision aid methods, PROMETHEE and GAIA, we will show that different preference parameters (given by the DM) lead to different rankings. Finally, a group decision can be reached using its extension: PROMETHEE GDSS.
\end{abstract}

Keywords: PROMETHEE, GAIA, ranking, statistical distribution, multi-criteria decision analysis

\section{Introduction}

A debate has arisen recently over the best method for selecting a probability distribution to represent a set of data (Ramanathan, 2005; Tofallis, 2008; Wang et al., 2004). Wang et al. (2004) have proposed a simple weighted additive model, whereas Ramanathan (2005) prefers data envelopment analysis and Tofallis (2008) supports a weighted multiplicative model. These three multi-criteria decision making methods produce a ranking (which may all be different) based on setting parameters distinctive to each method:

- The weighted additive model assumes linear indifference functions.

- The weighted multiplicative model has convex indifference curves, which favours compromises over extreme solutions.

- The data envelopment analysis (DEA) will, through a linear optimisation, choose weights which show each candidate under their best profile. Unlike the two other methods, it is not compensatory in the sense that bad scores may be ignored.

These three proposed methods have a prescriptive approach based on normative hypotheses, which are included in the method and do not depend neither on the data nor the type of problem. They aim to prescribe an optimal solution based on a rational model, established a priori to represent a simplified version of the reality. For example, in a weighted additive model, we assume that a $4 \%$ error is twice worse than a $2 \%$ error. In a multiplicative model, $4 \%$ is $n$ power (where $n$ is the weight of the criterion) worse than a $2 \%$ error. This is not

\footnotetext{
* Corresponding author
} 
[Pre-print version], please cite as: Ishizaka A., Nemery P. Selecting the best statistical distribution with PROMETHEE and GAIA, Computers \& Industrial Engineering, doi: 10.1016/j.cie.2011.06.008, Advance Online Publication

always the case: nor an additive neither a multiplicative modelling would be appropriate if break-downs take place only above $3 \%$ error. The expertise of the decision-maker is therefore essential to model the problem. In the American school (or classical school) of Multi-Criteria Decision Making (MCDM), the weighted additive model have been improved to incorporate the expertise and preferences of the decision-maker, for example in MAUT and AHP. However, these methods still keep the normalisation problem of the weighted additive model (Triantaphyllou, 2001; Wang \& Luo, 2009). In order to avoid the normalisation problem, outranking methods are used. They belongs to the French (or European) school and have also the advantage to prefer a constructive approach based on an interaction between the decisionmaker and an analyst (the specialist in decision aid methods) (e.g.(Vincke, 1992)). These methods belong to the Multi-Criteria Decision Aid (MCDA) field. Because real decision problems are complex, fuzzy, unclear and not well specified, it is not possible to have completely stable and defined preference system in the mind of the decision-maker before even beginning the decision aiding process. It is only during the decision process and its interactions with the analyst, that the structure of the problem will become clear. This jointly constructed model must be a tool for looking, exploring, interpreting, debating and even arguing the problem (Roy, 2009; Tsoukiàs, 2008). Then, the parameters characterising the preference model are defined. Several sets of parameters may be accepted or investigated in order to evaluate the impact of each one on the produced results. In the American conception, these parameters are predefined at the exception of the weights of the criteria and sometimes the utility functions. The French school certainly requires a longer process needing several revisions but the decision-maker will better understand the results and potentially explain and defend them (Roy, 1996).

PROMETHEE has already been used successfully in several cases. Behzadian et al. (2010) enumerated 195 papers, from its conception until 2008, where PROMETHEE is applied in environment management (47 papers), business and financial management (25), hydrology and water management (28), chemistry (24), logistics and transportation (19), manufacturing and assembly (19), energy management (17), social (7), design (2), agriculture (2), education (2), sports (1), information technology (1) and medicine (1) . Recently, PROMETHEE has been used in water management (Kodikara et al., 2010; Silva et al., 2010), banking (Doumpos \& Zopounidis, 2010), energy management (Ghafghazi et al., 2010; Oberschmidt et al., 2010), manufacturing and assembly (Kwak \& Kim, 2009; Saidi Mehrabad \& Anvari, 2010; Tuzkaya et al., 2010; Venkata Rao \& Patel, 2010; Zhu et al., 2010), logistics and transportation (Lanza \& Ude, 2010; Safaei Mohamadabadi et al., 2009; Semaan \& Zayed, 2010), quality (Nikolic et al.), chemistry (Cornelissen et al., 2009; Ni et al., 2009), maritime commerce (Castillo-Manzano et al., 2009), strategy (Ghazinoory et al., 2009), project management (Halouani et al., 2009), construction (Castillo-Manzano et al., 2009; Frenette et al., 2010), urban development (Juan et al., 2010), location analysis (Luk et al., 2010), environment (Nikolić et al., 2010; Soltanmohammadi et al., 2009; Zhang et al., 2010; Zhang et al., 2009), safety (Ramzan et al., 2009) and e-commerce (Andreopoulou et al., 2009). PROMETHEE method is on the basis of two sorting methods: Promsort (Araz \& Ozkarahan, 2007) and FlowSort (Nemery \& Lamboray, 2008).

As selecting a statistical distribution is a complex, fuzzy and unclear problem, which needs interactions with the decision-maker, PROMETHEE method complemented by GAIA (Brans \& Mareschal, 1994) is appropriate. This method permits easily the modelling of this decision problem according to the preferences of the decision-maker. Moreover, the developed software iDA (interactive Decision Analysis) supporting PROMETHEE and GAIA has a user-friendly graphical interface, which facilitates the interaction. 
[Pre-print version], please cite as: Ishizaka A., Nemery P. Selecting the best statistical distribution with PROMETHEE and GAIA, Computers \& Industrial Engineering, doi: 10.1016/j.cie.2011.06.008, Advance Online Publication

In this paper, we first discuss the methods proposed in the previous papers. In the next section, we present three different scenarios modelled with PROMETHEE and GAIA, which lead to different results. Then, we introduce PROMETHEE Group Decision Support System (GDSS) in order to incorporate the view of several decision-makers. Finally, we conclude the paper with a discussion on the advantages of the proposed approach.

\section{Review of proposed methods}

\subsection{Description of the problem}

The problem consists in the selection of a probability distribution to represent a set of data based on the following criteria:

- $\mathrm{D}_{\max }$ : the Kolmogorov-Smirnov statistic test,

- $\delta_{\mathrm{f}}$ : the average deviation between the theoretical probability distribution function and the empirical one,

- $\delta_{\mathrm{F}}$ : the average deviation between the theoretical cumulative distribution function and the empirical one,

- D: the deviation in skewness and kurtosis,

- E: a subjective score obtained from a group of experts in the field of study and statistics on the user friendliness of the distribution and the frequency of its use in the field, and the fitness of properties and characteristics of the distribution to the sampled data.

Wang et al.(2004) provides the following data from an engineering problem involving machine tools (table 1).

Table 1: Performances of each distribution

\begin{tabular}{|l|l|l|l|l|l|}
\hline Distribution & \multicolumn{1}{|c|}{$\mathbf{D}_{\max }$} & \multicolumn{1}{|c|}{$\boldsymbol{\delta}_{\mathbf{F}}$} & \multicolumn{1}{|c|}{$\boldsymbol{\delta}_{\mathbf{f}}$} & \multicolumn{1}{c|}{$\mathbf{D}$} & \multicolumn{1}{c|}{$\mathbf{E}$} \\
\hline Beta & 0.144612 & 0.000845215 & 0.0404891 & 2.79466 & 0.22 \\
\hline Gamma & 0.09821 & 0.000431302 & 0.0088562 & 0.66035 & 0.22 \\
\hline Weibull & 0.056581 & 0.000397474 & 0.0110291 & 1.288 & 0.18 \\
\hline Lognormal & 0.10316 & 0.000660129 & 0.0205139 & 3.15615 & 0.18 \\
\hline Normal & 0.404622 & 0.00172495 & 0.23522 & 4.06326 & 0.1 \\
\hline $\begin{array}{l}\text { Extreme- } \\
\text { value }\end{array}$ & 0.176833 & 0.00155293 & 0.0402712 & 1.03315 & 0.1 \\
\hline
\end{tabular}

It is not the scope of this paper to discuss these criteria. If appropriate, other criteria could be used. The focus here will be on the selection method.

\subsection{Weighted Sum Approach}

In a weighted sum approach, performances of the actions on each criterion are simply weighted according to the importance of the criteria and then added. When measures are not commensurate (like in table 1), a standardisation is necessary. Wang et al. (2004) proposes the transformation function:

$$
\mathrm{r}(v)=1 /\left(1+c v^{2}\right)
$$

where $c$ is a positive constant 
Ramanathan (2005) gives an example where different values of the constant $c$ lead to different final rankings. Tofallis (2008) adds that there are several ways of standardizing: $\mathrm{z}$ transformation, dividing the performances by their sum, dividing the performances by the highest performance, ... and all have merits and drawbacks but may lead to different results, without knowing the causal effect. To overcome this problem, approaches which do not require any standardization have been proposed.

The weighted sum approach is a very simple model, where the utility functions are linear positive. For example, a deviation of $4 \%$ is always twice worse than a deviation of $2 \%$ and four times worse than a deviation of $1 \%$. Furthermore, the incomparability is not considered but assimilated to indifference in this model as well as in the weighted multiplicative model. Two alternatives reaching the same score are said to be indifferent, even if the way they obtained this score is very different and therefore incomparable (Vincke, 1992).

\subsection{Data envelopment analysis}

Ramanathan (2005) proposes the use of the data envelopment analysis (DEA), which is an often used ranking technique (Adler et al., 2002; Mannino et al., 2008; Serrano-Cinca et al., 2005; Sueyoshi \& Goto, 2009a, 2009b) and does not require any normalisation and even any subjective input (e.g. weight of the criteria) from the user. However, Tofallis (2008) points out three major problems with DEA:

- DEA is not designed for selecting a single winner, it indicates only the non-dominated solutions,

- DEA may completely ignore the weakness of some candidates,

- DEA becomes less discriminating as more information is provided.

These remarks are only valid for the traditional radial DEA model. In fact, new models based on multiplier restriction (e.g., cone ratio, cross-efficiency, super-efficiency,...), which disallow extreme values, have been developed to reduce the number of efficient alternatives (or DMUs). It is possible to identify a single best alternative and to incorporate weakness of some candidate in the decision using DEA (Glover \& Sueyoshi, 2009; Sueyoshi \& Goto, 2009a, 2009b).

Nevertheless, with the several models developed, a problem remains as the rankings of alternatives depends upon which DEA model is used for the performance evaluation (Sueyoshi \& Sekitani, 2009). This choice may be cumbersome for the decision-maker and somehow random.

\subsection{Weighted Multiplicative approach}

Tofallis (2008) proposes multiplicative aggregation, which does not need any normalisation either. The multiplicative model is based on convex indifference curves, which are also called Cobb-Douglas in economics (Varian, 1999). In this case, compromises are preferred over extremes. For example, where a person is indifferent (same weight) to apples and pears, (s)he would prefer a crate with 5 apples and 4 pears (total score is $5 \cdot 4=20$ ) over a crate with 15 apples and 1 pear (total score is $15 \cdot 1=15$ ). This seems illogical as the preferred alternative has far lower total number of fruits (9 against 16 fruits). Again, this model imposes preferences to the decision-maker that may not represent his/her preferences. 
[Pre-print version], please cite as: Ishizaka A., Nemery P. Selecting the best statistical distribution with PROMETHEE and GAIA, Computers \& Industrial Engineering, doi: 10.1016/j.cie.2011.06.008, Advance Online Publication

\section{PROMETHEE and GAIA}

The PROMETHEE method belongs to the outranking family (Vincke 1992). The actions are first pair-wise compared on each criterion according to the decision-maker's preferences, resulting to local scores. These local scores are then aggregated to a global score, which lead to the PROMETHEE I or PROMETHEE II ranking (Brans, 1982; Brans \& Vincke, 1985). In PROMETHEE I, the resulting ranking is a partial pre-order whereas in PROMETHEE II the resulting ranking is a complete pre-order.

Usually, this prescriptive approach is combined with a descriptive approach, the GAIAmethod. We describe briefly these two methods but refer the interested reader to (Brans \& Mareschal, 1994, 2005) for more detailed information about these two methods.

\subsection{PROMETHEE}

We consider a problem with a set of possible actions $A=\{a, b, \ldots\}$ which are evaluated on a set of $k$ criteria $F=\left\{f_{1}, f_{2}, \ldots, f_{k}\right\}$. We can suppose, without loss of generality that all the criteria have to be maximized.

A decision-maker expresses his preference of action $a$ over action $b$ considering the criterion $f_{j}$ by computing a single-criterion preference degree $P_{j}(a, b)$ which is in function of $d_{j}(a, b)=$ $f_{j}(a)-f_{j}(b)$. The value of this preference function $P_{j}(a, b)$ is included between 0 and 1 , with:

\section{$\left\{\begin{array}{l}P_{j}(a, b) \approx 0 \text { if action } a \text { is not strictly preferred to action } b \\ P_{j}(a, b) \approx 1 \text { if action } a \text { is highly preferred to action } b\end{array}\right.$}

Several typical shapes are proposed (Brans \& Mareschal, 2005) for the preference functions like the linear, the step or Gaussian preference function (see figure 1 for the linear function).

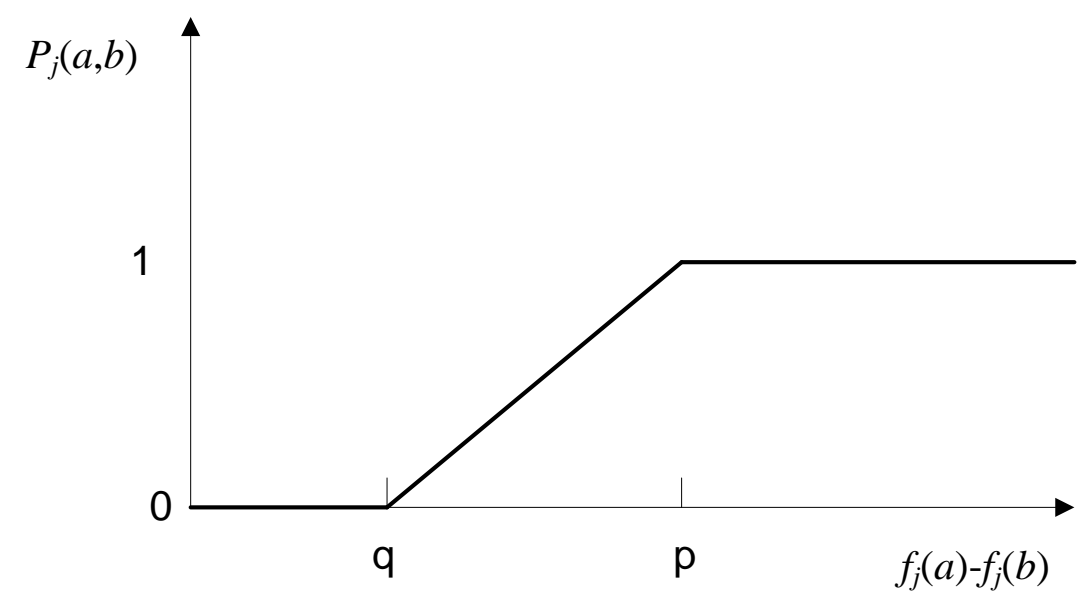

Figure 1: Preference linear function where $q$ and $p$ represent respectively the indifference and preference thresholds. $f_{j}(a)$ denotes the performances of action $a$ on criterion $j$ and $P_{j}(a, b)$ the preference of action $a$ over $b$ on criterion $f_{j}$.

These pair-wise comparisons are aggregated to the positive and negative flows by using the weights $w_{j}$ defined by the decision-maker:

Positive flow:

$$
\phi^{+}(a)=\frac{1}{\llbracket A \rrbracket-1} \sum_{x \in A} \sum_{j=1}^{k} w_{j} P_{j}(a, x)
$$


[Pre-print version], please cite as: Ishizaka A., Nemery P. Selecting the best statistical distribution with PROMETHEE and GAIA, Computers \& Industrial Engineering, doi: 10.1016/j.cie.2011.06.008, Advance

Online Publication

where $\|A\|: \quad$ cardinal of the set of actions $A$

$w_{j}$ : $\quad$ weight of criteria $f_{j}$

$P_{j}(a, x)$ : preference of action $a$ over $x$ on criterion $f_{j}$.

$k$ : $\quad$ number of criteria

This score represents the global strength of action $a$ in comparison to all the other actions. Indeed, this score has to be maximised.

Negative flow:

$$
\begin{array}{ll}
\phi^{-}(a)=\frac{1}{\llbracket A \|-1} \sum_{x \in A} \sum_{j=1}^{k} w_{j} P_{j}(x, a) \\
\text { where }|A|: \quad \text { cardinal of the set of actions } A \\
w_{j}: \quad \text { weight of criteria } f_{j} \\
P_{j}(a, x): & \text { preference of action } a \text { over } x \text { on criterion } f_{j} . \\
k: & \text { number of criteria }
\end{array}
$$

This score represents the global weakness of $a$ in comparison to all the other actions. Indeed, this score has to be minimised.

The PROMETHEE I partial ranking is defined as follows:

$$
\begin{array}{ll} 
& a \text { is preferred to } b \text { iif. } \phi^{+}(a)>\phi^{+}(b) \text { and } \phi^{-}(a)<\phi^{-}(b) \\
& a \text { is indifferent to } b \text { iif. } \phi^{+}(a)=\phi^{+}(b) \text { and } \phi^{-}(a)=\phi^{-}(b) \\
& a \text { is incomparable to } b \text { iif. } \quad \phi^{+}(a)>\phi^{+}(b) \\
\phi^{-}(a)>\phi^{-}(b) \text { or } & \\
\phi^{+}(a)<\phi^{+}(b) \text { and } \phi^{-}(a)<\phi^{-}(b)
\end{array}
$$

However, the two flows are usually combined to obtain the net flows defined as follows:

$$
\phi(a)=\phi^{+}(a)-\phi^{-}(a)
$$

which leads to the complete PROMETHEE II pre-order:

$$
\begin{array}{ll}
a \text { is preferred to } b \text { iif. } & \phi(a)>\phi(b) \\
a \text { is indifferent to } b \text { iif. } & \phi(a)=\phi(b)
\end{array}
$$

Let us remark that the net flow can also be written as (Mareschal et al., 2008):

$$
\phi(a)=\frac{1}{|A|-1} \sum_{j=1}^{k} w_{j} \phi_{j}(a)
$$

where $\phi_{j}(a)=\sum_{x \in A}\left(P_{j}(a, x)-P_{j}(x, a)\right)$ is the single criterion net flow of criterion $j$.

These single criterion net flows may be summarized for each action and each criterion in the following matrix (Brans \& Mareschal, 1994): 
[Pre-print version], please cite as: Ishizaka A., Nemery P. Selecting the best statistical distribution with PROMETHEE and GAIA, Computers \& Industrial Engineering, doi: 10.1016/j.cie.2011.06.008, Advance Online Publication

$$
\Phi=\left(\begin{array}{cccccc}
\phi_{1}(a) & \phi_{2}(b) & \cdots & \phi_{j}(k) & \cdots & \phi_{k}(n) \\
\phi_{1}(a) & \phi_{2}(b) & \cdots & \phi_{j}(k) & \cdots & \phi_{k}(n) \\
\cdots & \cdots & \cdots & \cdots & \cdots & \cdots \\
\phi_{1}(a) & \phi_{2}(b) & \cdots & \phi_{j}(k) & \cdots & \phi_{k}(n) \\
\cdots & \cdots & \cdots & \cdots & \cdots & \cdots \\
\phi_{1}(a) & \phi_{2}(b) & \cdots & \phi_{j}(k) & \cdots & \phi_{k}(n)
\end{array}\right)
$$

This matrix is similar to a performance table since each row $a_{i}$ of this matrix represents an action $i$ and each column represents a criterion. This matrix contains indeed preference information given by the decision-maker but does not provide inter-criteria information (i.e., how the actions behave on all the criteria simultaneously).

\subsection{GAIA}

The aim of the GAIA method is to represent on a two dimensional view as much as possible the decision- maker's preferences and its implications (Brans \& Mareschal, 1994). For this purpose, a plane in the hyperspace is found with the principal component analysis (PCA) of the matrix $\Phi$. In the PCA, the variance-covariance matrix of the decision problem, noted $\mathrm{C}$, is at first calculated. This matrix can be obtained by using the following relation:

$$
n \mathrm{C}=\Phi^{\prime} \Phi
$$

$$
\begin{gathered}
\text { where } C: \text { variance-covariance matrix } \\
\Phi^{\prime}: \text { the transposed matrix of } \Phi \\
n: \text { positive integer }
\end{gathered}
$$

Then, two eigenvectors, noted $\vec{u}$ and $\vec{v}$, are selected such as they have the greatest eigenvalues $\lambda_{1}$ and $\lambda_{2}$. These two eigenvectors are orthogonal $(\vec{u} \perp \vec{v})$ and define the best plane, called the GAIA plane, to use for the projection of the actions (the $a_{i}$ points) while minimising the loss of information (Brans \& Mareschal, 1994).

Every action of the decision problem will be projected in this plane and its coordinates are obtained as follows:

$$
\begin{aligned}
& \left\{\begin{array}{l}
\left|\overrightarrow{O p_{i}}\right|=\overrightarrow{a_{i}^{t}} * \vec{u} \\
\left|\overrightarrow{O q_{2}}\right|=\overrightarrow{a_{i}^{\prime}} * \vec{v}
\end{array}\right. \\
& \text { where } \overrightarrow{a_{i}^{t}} \text { : transposed row } i \text { of matrix } \Phi
\end{aligned}
$$

In order to represent the intra criteria information, each criterion $f_{j}$ will be projected to $c_{j}$ on the GAIA plane. The angle between the projections of two criteria is a measure of similarity or conflict between the criteria. The smaller the angle, the more similar two criteria are. A large angle means conflicting criteria.

Finally, the information on the weights chosen by the decision-maker can be added by finding the projection of the weights vector: $\vec{w}:\left(w_{1}, w_{2}, \ldots, w_{j}, \ldots, w_{k}\right)$. The obtained vector is called Decision Stick, noted $\vec{D}$, and represents the decision-maker's priorities:

$$
\vec{D}:(\vec{w} * \vec{u}, \vec{w} * \vec{v})
$$


The GAIA plane facilitates the decision aid process as easy conclusions can be drawn visually. Near actions on the plane will often have very similar rows in the variancecovariance matrix $\Phi$. The decision-maker can thus easily identify actions with similar or opposite performances. Moreover, the decision-maker can compare criteria since their position on the plane is an indication of their conflicting or correlated behaviour. Their length represents their distinguishing power between actions. A wash criterion has a short length; a discriminating criterion has a long length.

\subsection{PROMETHEE GDSS}

The PROMETHEE Group Decision Support System (GDSS) permits to rank actions according to several criteria and decision-makers (Macharis et al., 1998). In fact, in this approach each individual ranking given by the net flows is considered as a criterion. So, for each decision-maker, the net flow vector (4) is collected in a global investigation matrix and PROMETHEE II (see section 3.1) is applied on it. Each decision-maker (i.e. criterion) may have the same or a different weight.

\section{Selection of the best distribution}

In this section, we will present four scenarios, where three hypothetical DM expresses different preference parameters. As the purpose of the exercise is to illustrate the advantages of the methods, the parameters are selected in order to highlight them but still keeping them into a plausible range. In a real application, they would be selected in accordance to the set of data, the problem where the probability distribution would be used on, the expertise of the decision-maker, the range of the acceptable errors,... In the first scenario, we observe the same ranking than Wang (2004). In the second one, other preferences functions are introduced (with the same weights) which leads to a swap of the two best ranked actions. In the third scenario, weights and preferences functions are changed, which leads to another ranking with incomparabilities. In the last scenario, the view of all first three scenarios is incorporated in PROMETHEE GDSS for a group decision.

\section{Scenario 1}

The first scenario uses the values of table 1 , and the weights proposed by Wang: $w:(0.18$, $0.28,0.28,0.13,0.13)$. All the criteria have to be minimized apart $\mathrm{E}$, the score given by the group of experts. Let us suppose at first that the decision-maker chooses for each criterion the usual preference function (see figure 1 , with indifference $\mathrm{q}$ and preference $\mathrm{p}$ thresholds $=0$ ). This means that the preference function $P_{j}(a, b)=0$ only if the actions are identical on criterion $j$, otherwise $P_{j}(a, b)=1$. In other words, small or large criteria differences have the same effect. These parameters lead to the results represented in the figure 2 and table 2 .

Table 2: Positive, negative and net flows for scenario 1

\begin{tabular}{|l|l|l|l|l|}
\hline Rank & Distribution & $\phi^{+}()$. & $\phi^{-}(\mathrm{s})$ & $\phi(\mathrm{s})$ \\
\hline 1 & Gamma & 0.882 & 0.092 & 0.79 \\
\hline 2 & Weibull & 0.814 & 0.16 & 0.654 \\
\hline 3 & Lognormal & 0.522 & 0.452 & 0.07 \\
\hline 4 & Beta & 0.396 & 0.578 & -0.182 \\
\hline 5 & Extreme Values & 0.308 & 0.666 & -0.358 \\
\hline 6 & Normal & 0 & 0.974 & -0.974 \\
\hline
\end{tabular}


[Pre-print version], please cite as: Ishizaka A., Nemery P. Selecting the best statistical distribution with PROMETHEE and GAIA, Computers \& Industrial Engineering, doi: 10.1016/j.cie.2011.06.008, Advance Online Publication

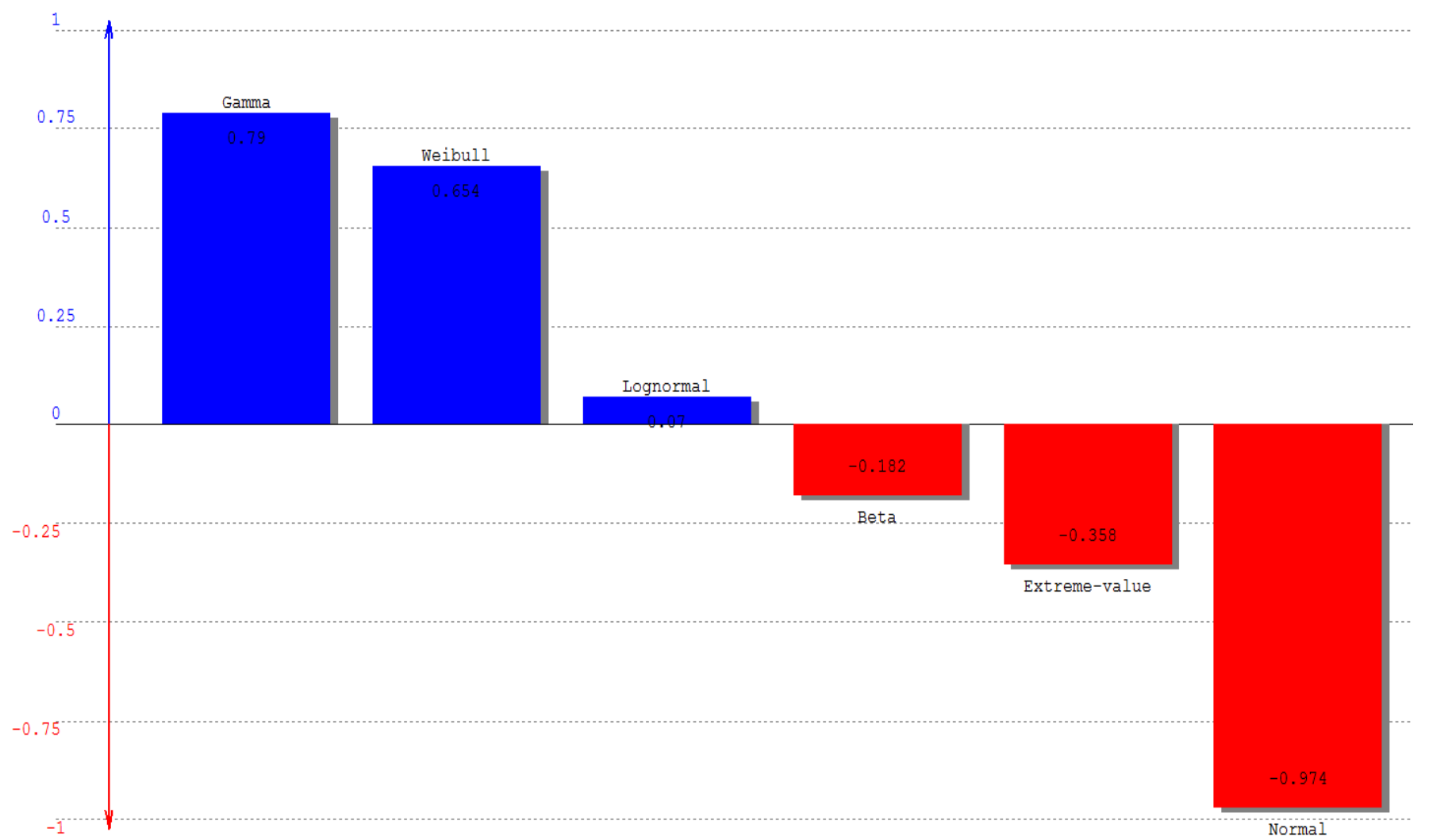

Figure 2: Net flows for Scenario 1.

From table 2 and figure 2, we may notice that the Gamma distribution is the recommended choice, followed closely by the Weibull distribution. The other distributions are far away. This ranking is the same ranking than those obtained in Wang and al. (2004). In this particular case, the ranking of PROMETHEE I and II are identical (all the flows give the same ranking) and complete (there is no incomparability). Figure 3 shows the contribution of each criterion to the net flow. All the contributions are positive for the Gamma and the Weibull distribution. The Gamma distribution scores very high on the $\delta_{\mathrm{f}}$ criterion whilst the Weibull distribution is stronger on the $\delta_{\mathrm{F}}$ criterion. All the contributions are negative for the Normal distribution. Some contributions are positive and some are negative for the Lognormal, the Beta and the Extre-value distribution. Therefore the black point, indicating their net flow is not on one extremity of the pile on the figure 3 . 
[Pre-print version], please cite as: Ishizaka A., Nemery P. Selecting the best statistical distribution with PROMETHEE and GAIA, Computers \& Industrial Engineering, doi: 10.1016/j.cie.2011.06.008, Advance Online Publication

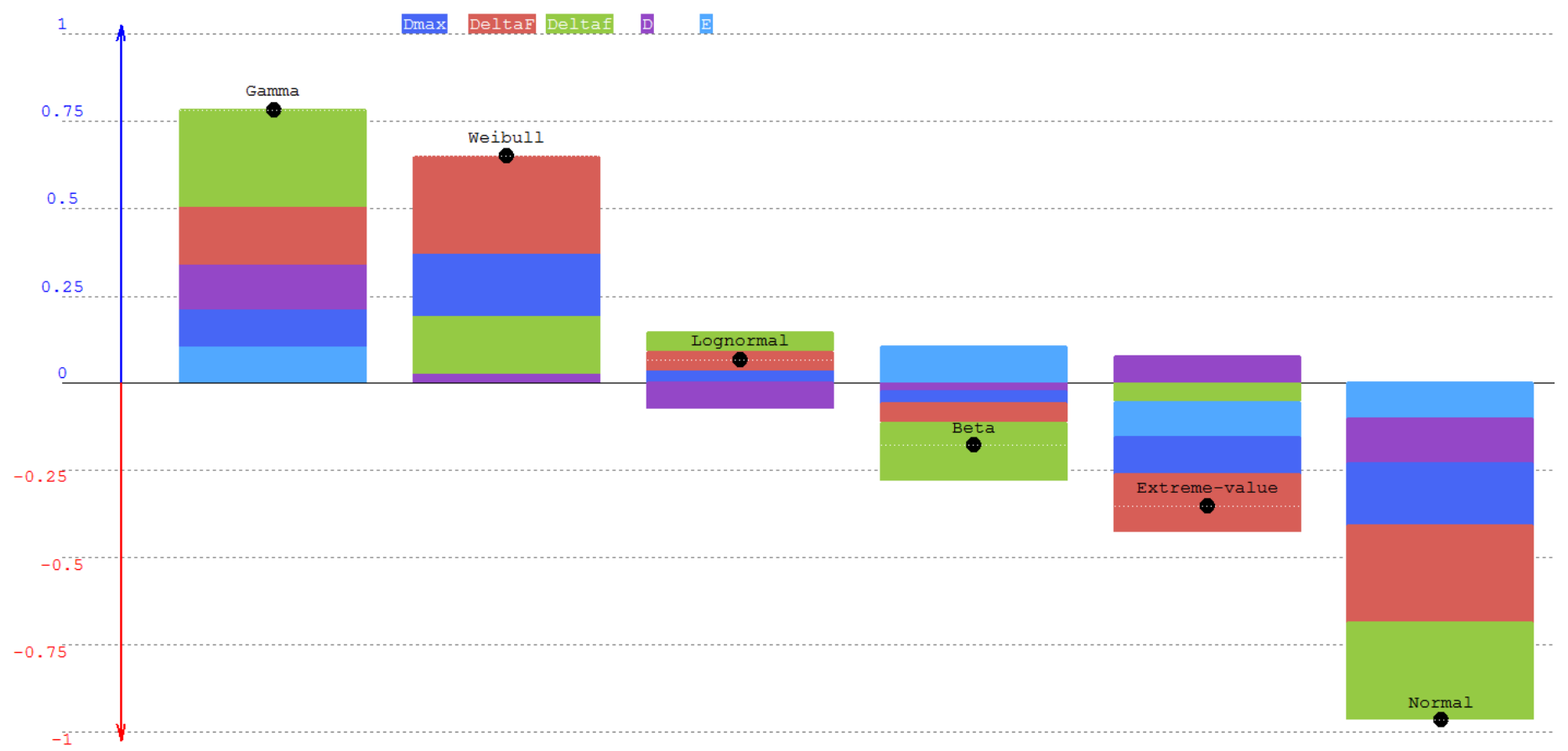

Figure 3: Composition of the unicriterion net flows for Scenario 1.

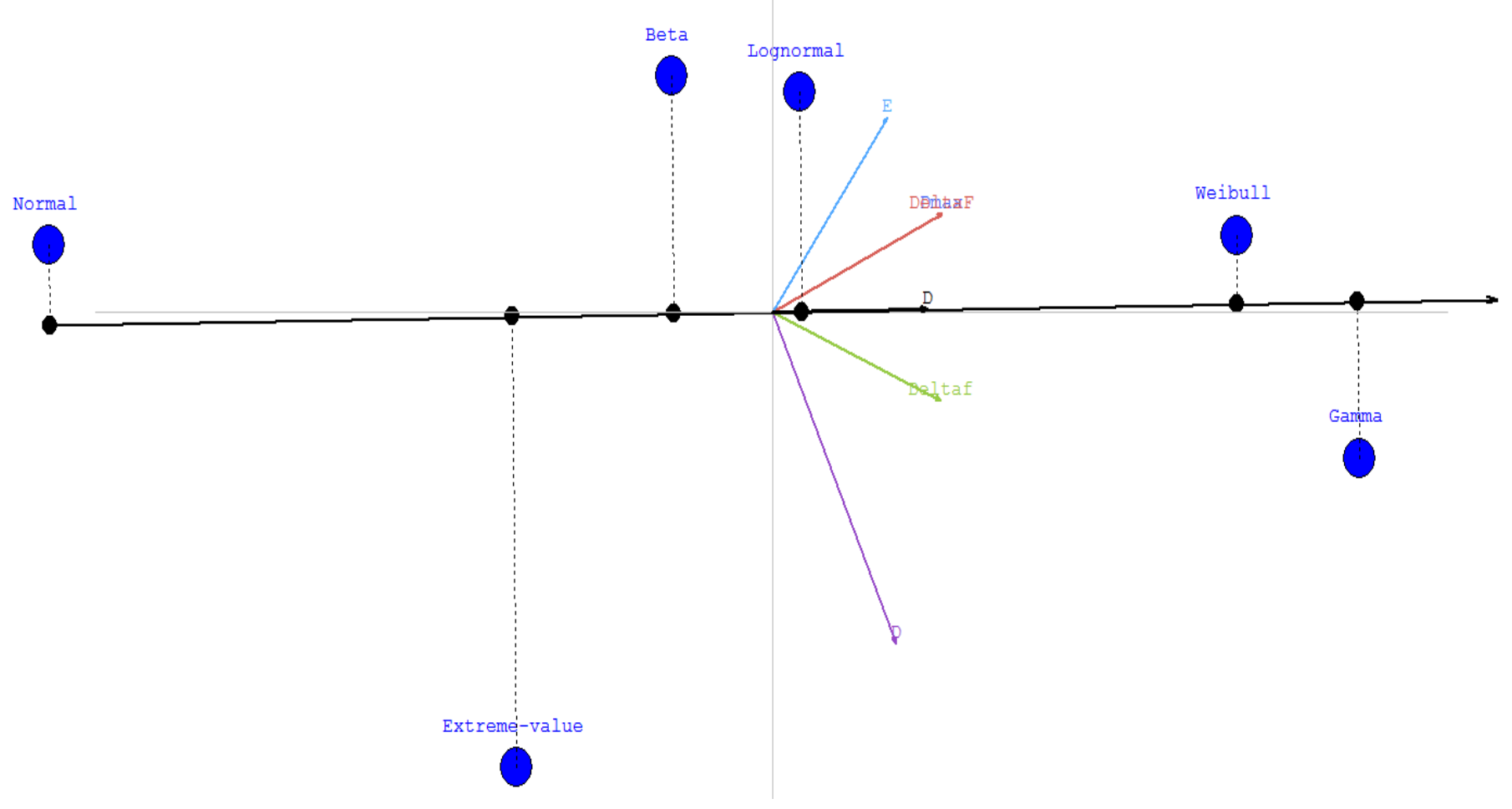

Figure 4: GAIA plane for scenario 1.

From the GAIA plane (figure 4) we can conclude that criterion D is highly conflicting with criterion $\mathrm{E}$ since their projections have a large angle. $\mathrm{D}_{\max }$ and $\delta_{\mathrm{F}}$ distinguish the actions in the same way (their projections are superposed). Given this set of parameters, the Normal 
[Pre-print version], please cite as: Ishizaka A., Nemery P. Selecting the best statistical distribution with PROMETHEE and GAIA, Computers \& Industrial Engineering, doi: 10.1016/j.cie.2011.06.008, Advance Online Publication

distribution is strongly different from all the other distributions whereas the Beta and Lognormal distributions are relatively close. Moreover, the Extreme Values distribution is at the opposite from the Beta and Lognormal distributions. This indicates that they have different features.

The Normal distribution is clearly outperformed by all the other distributions as it is in the opposite direction of the Decision Stick D (in black on the figure 4). The Gamma distribution performs the best on criteria $\delta_{\mathrm{f}}$ and $\mathrm{D}$, as it is projected on the same direction. The Weibull distribution on the other hand, performs much better on $\mathrm{D}_{\max }, \delta_{\mathrm{F}}$ and $E$. The best actions are the Weibull and Gamma distribution but they have different strengths.

\section{Scenario 2}

Let us now consider that the decision-maker expresses different preference parameters which are given in table 3. The weights are the same than in (Wang et al., 2004) but the preference functions and their associated thresholds are modified.

Table 3: Preference parameters for scenario 2.

\begin{tabular}{|l|l|l|l|l|l|}
\hline & \multicolumn{1}{|c|}{$\mathrm{D}_{\max }$} & \multicolumn{1}{c|}{$\boldsymbol{\delta}_{\mathrm{F}}$} & \multicolumn{1}{c|}{$\boldsymbol{\delta}_{\mathrm{f}}$} & \multicolumn{1}{c|}{$\mathrm{D}$} & \multicolumn{1}{c|}{$\mathrm{E}$} \\
\hline Weight & 0.18 & 0.28 & 0.28 & 0.13 & 0.13 \\
\hline Preference Function & Usual & Linear & Step & Gaussian & Linear \\
\hline $\mathrm{p}$ & 0 & 0.00132 & 0.226368 & $/$ & 0.1 \\
\hline $\mathrm{q}$ & 0 & 0 & 0.05 & 3 & 0 \\
\hline
\end{tabular}

The consequences of changing the preference functions are directly visible in the GAIA plane (figure 5). As the usual function highly distinguishes the actions, we may notice that the projection of $\mathrm{D}_{\max }$ is bigger than the projections of $\delta_{\mathrm{f}}$ and $\mathrm{D}$, where small differences are negligible. Given the data and the preference threshold of $\mathrm{E}$, we remark that this preference function distinguishes significantly the actions on the criterion $\mathrm{E}$, which explains its long projection. Choosing an indifference threshold of 0.05 for $\delta_{\mathrm{f}}$ (table 3 ) leads to the fact that most of the actions are indifferent on this criterion; the length of $\delta_{\mathrm{f}}$ is thus very small. Besides, one may notice that the Normal and Extreme Values distribution are now much closer than in scenario 1. Although the Beta and Lognormal scores (table 4) are closer than in scenario 1 (table 2), their spatial location on the GAIA plane is further in this scenario. GAIA has the descriptive power to detect actions with different behaviour on the criteria, which cannot be revealed by the final net flow.

In this scenario, the Weibull distribution is now first instead of the Gamma distribution. These consequences are indeed due to the preference parameters given by the decisionmaker. Let us remember that the weights are the same as in scenario 1 which pinpoints the importance of the other preference parameters: preference functions and thresholds. 
[Pre-print version], please cite as: Ishizaka A., Nemery P. Selecting the best statistical distribution with PROMETHEE and GAIA, Computers \& Industrial Engineering, doi: 10.1016/j.cie.2011.06.008, Advance Online Publication

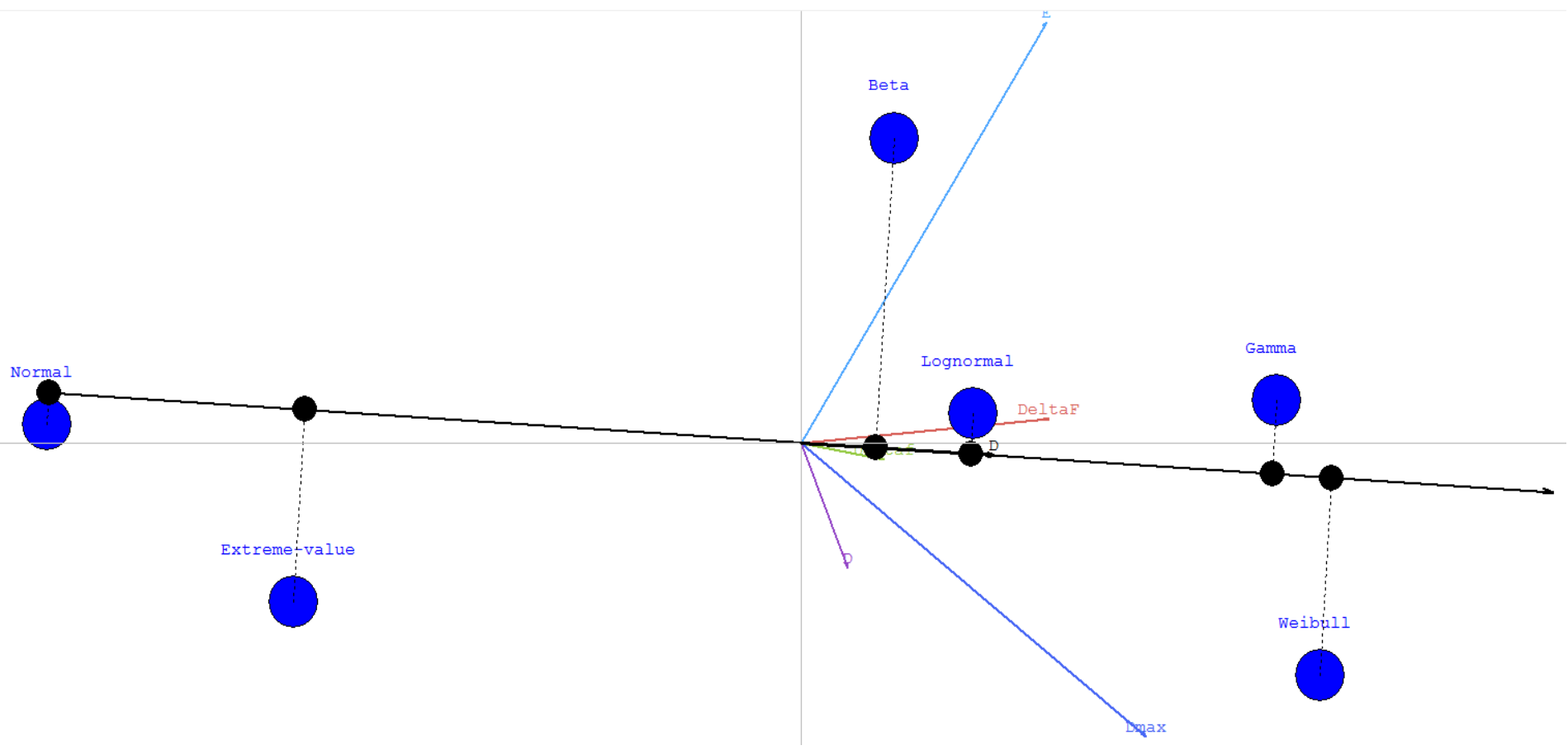

Figure 5: GAIA plane for scenario 2.

The flows for scenario 2 are given in table 4. One may thus notice, that compared to the scenario 1 and (Wang et al., 2004), the two first actions (Weibull and Gamma) have a different ranking. This difference is normal as the decision-makers of scenario 1 and 2 have different preferences. As in scenario 1, there is no difference between the rankings of PROMETHEE I and II.

Table 4: Positive, Negative and Net Flows for scenario 2.

\begin{tabular}{|l|l|l|l|}
\hline & $\phi^{+}()$ & $\phi^{-}()$ & $\phi()$. \\
\hline A3 - Weibull & 0.402 & 0.021 & 0.381 \\
\hline A2 - Gamma & 0.4 & 0.037 & 0.363 \\
\hline A4 - Lognormal & 0.269 & 0.132 & 0.137 \\
\hline A1 - Beta & 0.242 & 0.165 & 0.077 \\
\hline A6 - Extreme Values & 0.092 & 0.401 & -0.31 \\
\hline A5 - Normal & 0 & 0.649 & -0.649 \\
\hline
\end{tabular}

Figure 6 indicates the composition of the the unicriterion net flows. In particular, the Weibull distribution is scoring first because of its high scores on the criteria Dmax and $\delta_{\mathrm{F}}$. 
[Pre-print version], please cite as: Ishizaka A., Nemery P. Selecting the best statistical distribution with PROMETHEE and GAIA, Computers \& Industrial Engineering, doi: 10.1016/j.cie.2011.06.008, Advance Online Publication

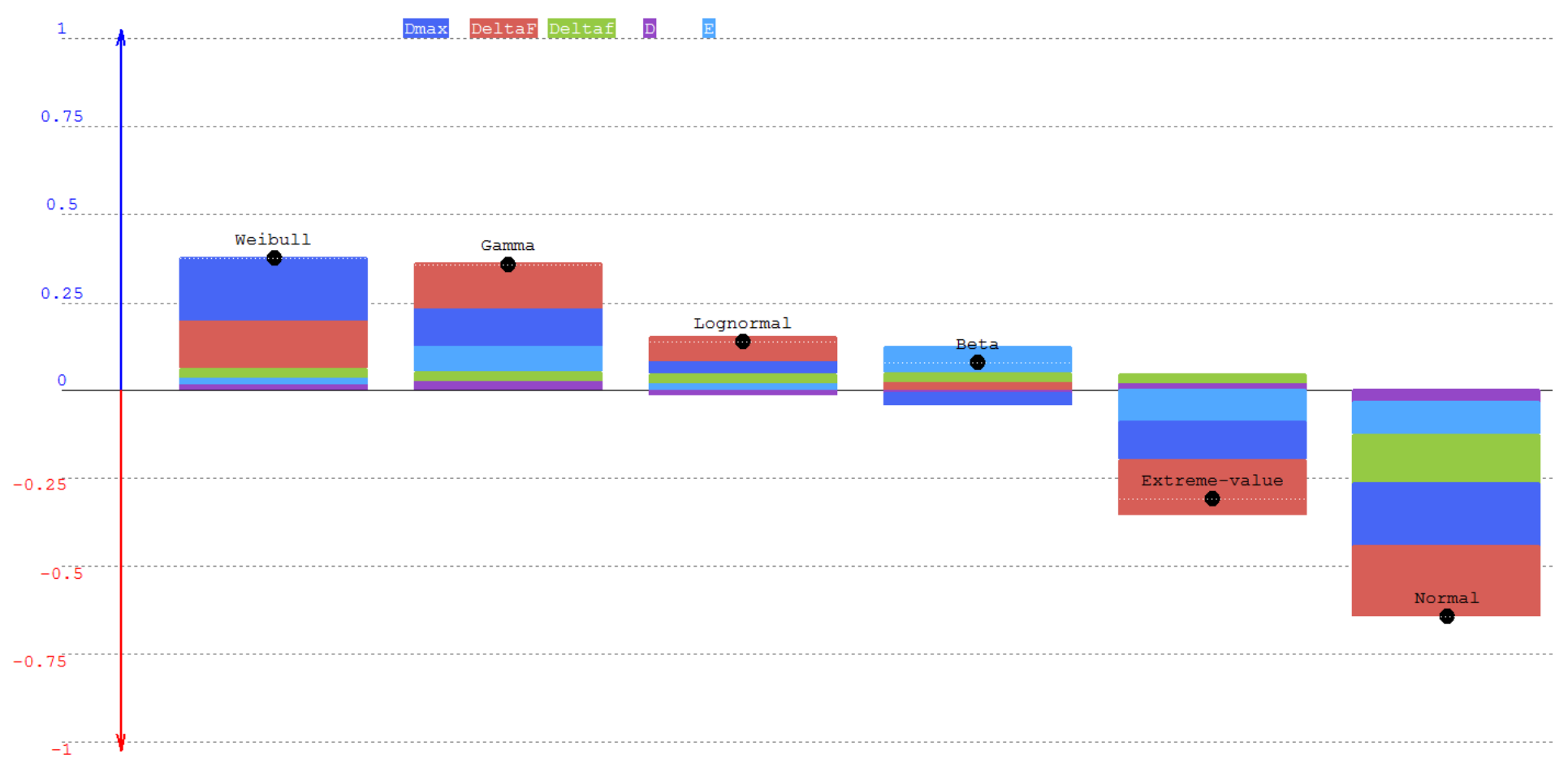

Figure 6: Composition of the unicriterion net flows for scenario 2.

\section{Scenario 3}

Let us now consider that the decision-maker expresses different preference parameters and weights which are given in table 5. Moreover, in this scenario 3 we do not take into account the advice of the expert (E) as done in Ramanathan (2005).

Table 5: Preference parameters for scenario 3.

\begin{tabular}{|l|l|l|l|l|}
\hline & \multicolumn{1}{|c|}{$\mathrm{D}_{\max }$} & \multicolumn{1}{c|}{$\delta_{\mathrm{F}}$} & \multicolumn{1}{c|}{$\delta_{\mathrm{f}}$} & \multicolumn{1}{c|}{$\mathrm{D}$} \\
\hline Weight & 0.233 & 0.147 & 0.15 & 0.471 \\
\hline Preference function & Linear & Linear & Step & Gaussian \\
\hline $\mathrm{p}$ & 0.348041 & 0.00132 & 0.226368 & N/A \\
\hline $\mathrm{q}$ & 0.3 & 0 & 0.2 & 3 \\
\hline
\end{tabular}




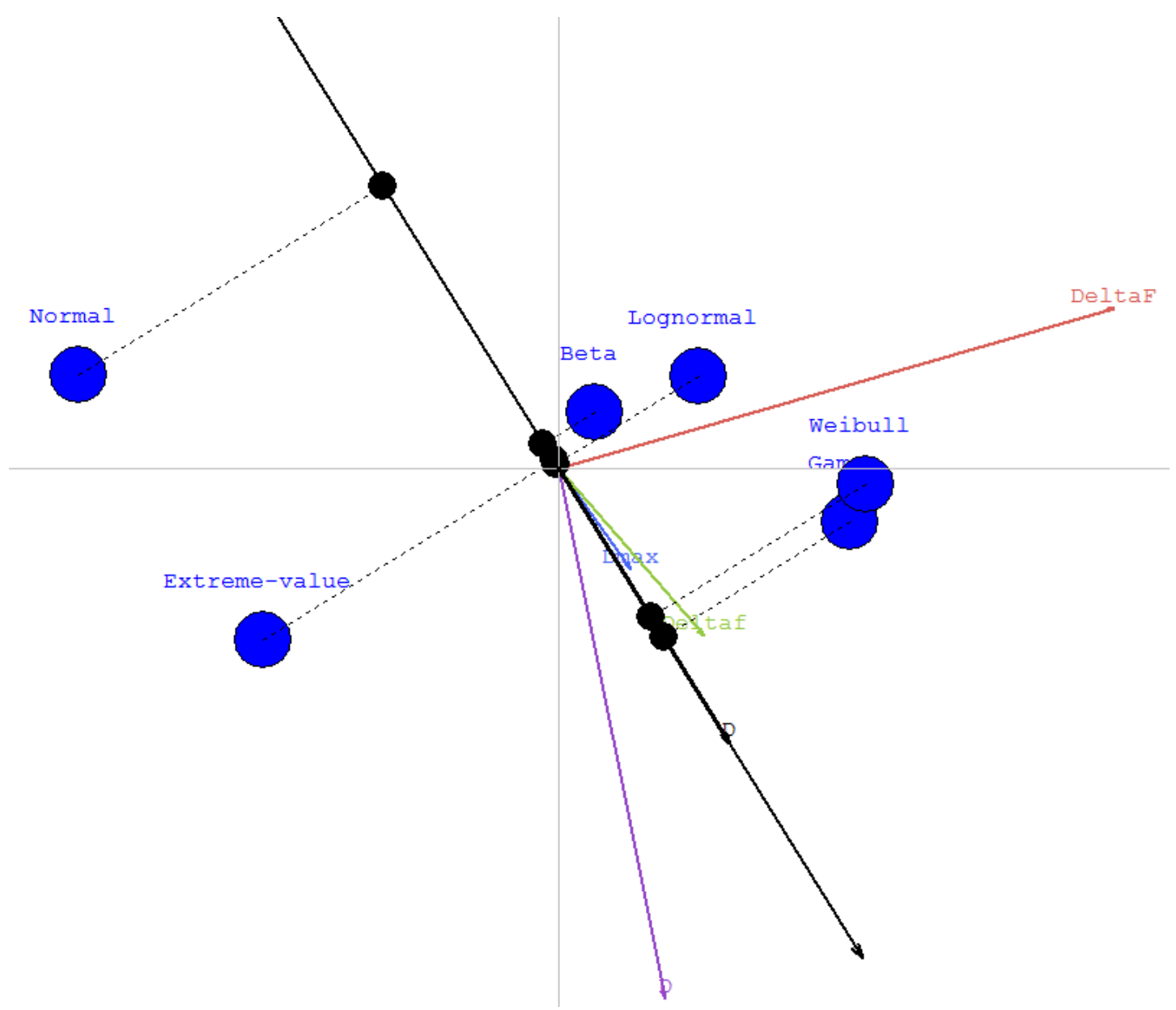

Figure 7: GAIA plane for scenario 3.

All differences between two actions measured on the criteria $D_{\max }$ and $\delta_{\mathrm{f}}$ falling below the indifference threshold (which is not zero), are considered as negligible. The Gaussian function used for the criterion D implies that small differences are considered negligible and large differences are significant. It explains why on GAIA plane (figure 7) the Weibull and Gamma distribution like the Lognormal and the Beta distribution behave similarly on $\mathrm{D}$, which was not the case on the two previous scenarios. The length of the projections of criteria $\mathrm{D}$, and $\delta_{\mathrm{F}}$ explains that the preference functions lead to a better differentiation on these criteria. Finally, a stronger weight on criterion D leads to a new orientation of the Decision Stick which is closer to the projection of D. The Lognormal and Extreme Values distribution have the same projection on the Decision Stick (which is confirmed by the same net flow in table 6) although they have different features (they are in a different spatial position on the GAIA plane). The Lognormal distribution performs very well on criterion $\delta_{\mathrm{F}}$ whereas the Extreme Values distribution excels on criterion D.

The Beta and Lognormal distribution have slightly different net flows (see table 6 or figure 8 and confirmed in figure 7 by their projection on the Decision Stick) but behaves similarly (in regards of their projections in the GAIA plane) in comparison to the other actions. In PROMETHEE I (figure 9 and table 6), one may notice that Extreme Values, Lognormal and Beta distributions are incomparable as well as the Weibull and Gamma distribution because the ranking of the positive and negative flows are different. We have thus a partial ranking in this scenario where the first two actions are globally incomparable. However, in the 
[Pre-print version], please cite as: Ishizaka A., Nemery P. Selecting the best statistical distribution with PROMETHEE and GAIA, Computers \& Industrial Engineering, doi: 10.1016/j.cie.2011.06.008, Advance Online Publication

PROMETHEE II ranking, the Weibull distribution is the best action. The ranking is similar to the one obtained in Tofallis (2008) at the exception of the first two actions, which are reversed.

Table 6: Positive, negative and net flows for scenario 3.

\begin{tabular}{|l|l|l|l|}
\hline & $\phi^{+}()$ & $\phi^{-}()$ & $\phi()$ \\
\hline Weibull & 0.193 & 0.002 & 0.191 \\
\hline Gamma & 0.185 & 0.001 & 0.184 \\
\hline Extreme Values & 0.077 & 0.086 & -0.009 \\
\hline Lognormal & 0.068 & 0.077 & -0.008 \\
\hline Beta & 0.044 & 0.07 & -0.026 \\
\hline Normal & 0 & 0.331 & -0.332 \\
\hline
\end{tabular}

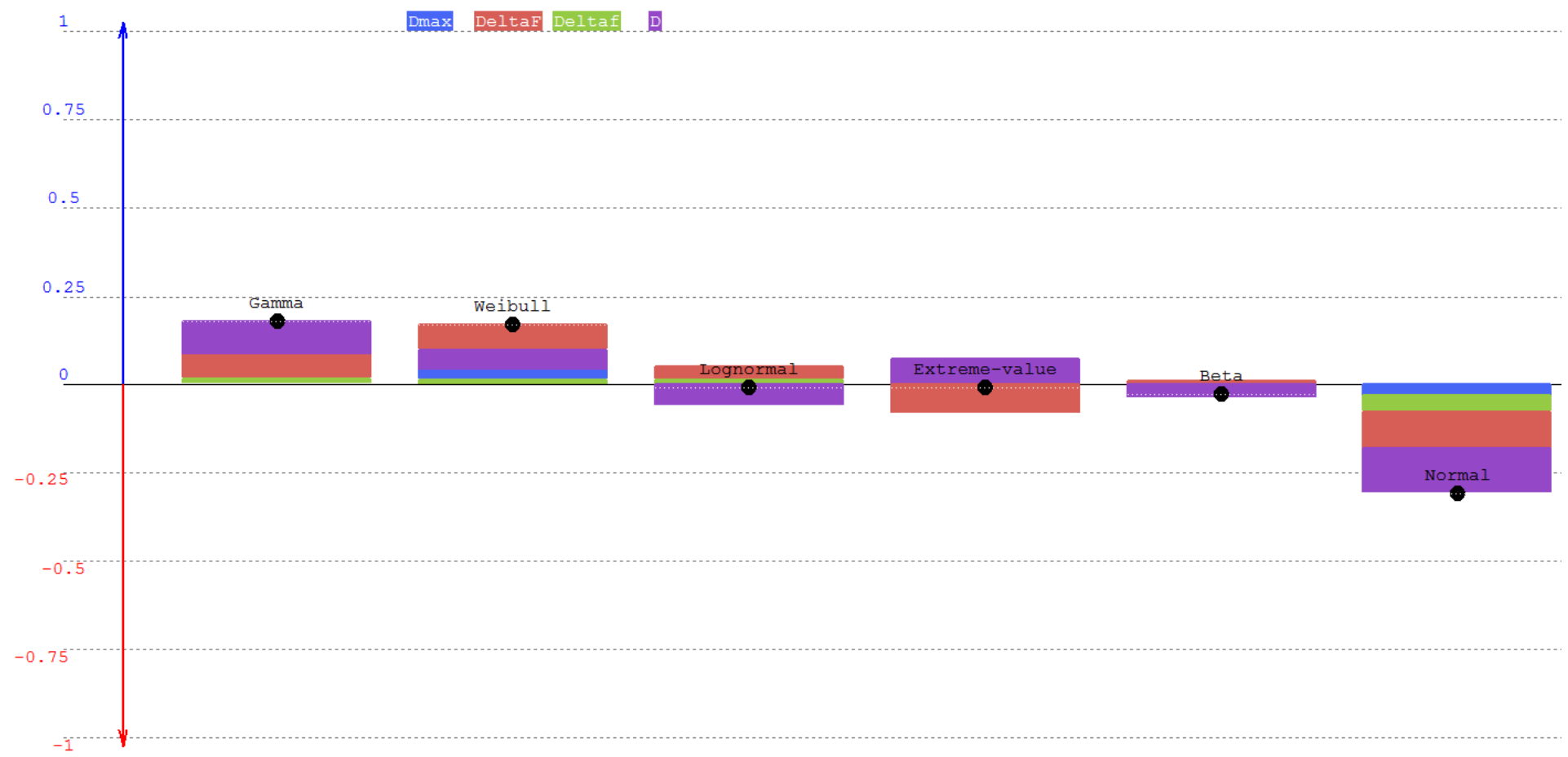

Figure 8: Representation of the net flows for scenario 3.

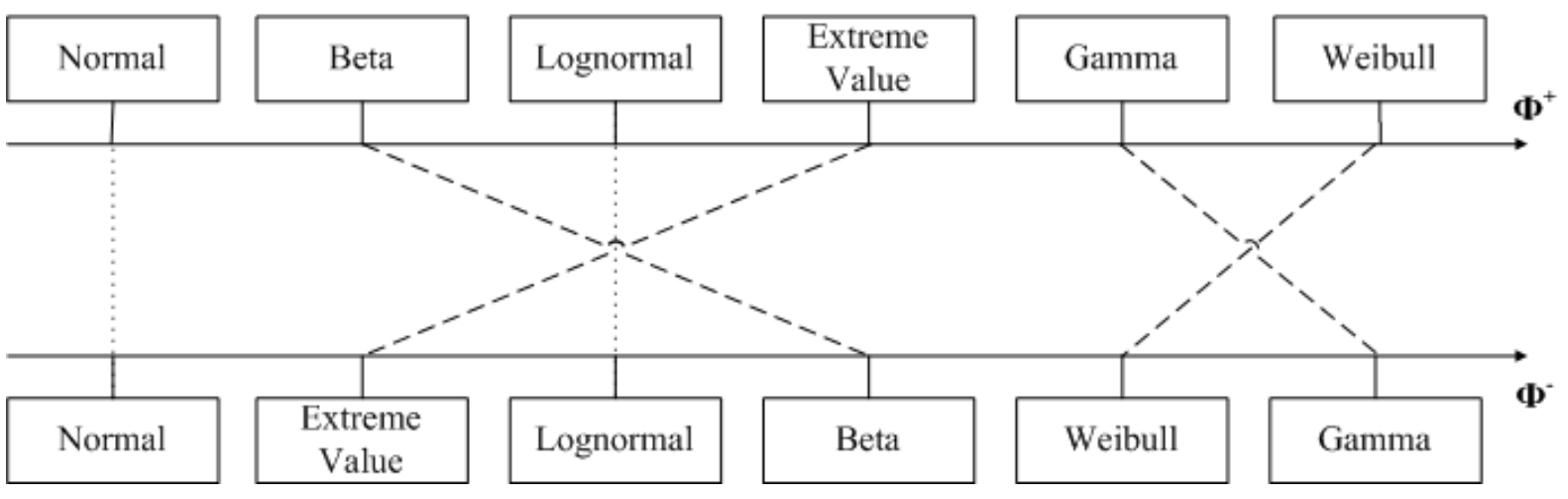

Figure 9: Representation of the PROMETHEE I flows ranking of scenario 3 
[Pre-print version], please cite as: Ishizaka A., Nemery P. Selecting the best statistical distribution with PROMETHEE and GAIA, Computers \& Industrial Engineering, doi: 10.1016/j.cie.2011.06.008, Advance Online Publication

\section{Scenario 4: PROMETHEE GDSS}

In the last scenario, we will consider the problem as a group decision, where it incorporates the individual opinion of the three previous decision-makers described in the scenarios 1-3. The decision-makers have thus different preference parameters. As we consider each participant having the same expertise, they receive the same weight. The actions are identical but the decision-makers become now the criteria. The unicriterion net flows of each action correspond to the net score of each action for a particular decision-maker. The net flows in table 2, 4 and 6 are the thus scores of each criterion. Table 7 gives the net flows and figure 10 shows its composition, made up by the net flow of each decision-maker (scenarios).

Table 7: Positive, negative and net flows for scenario 4.

\begin{tabular}{|l|l|l|l|}
\hline & $\phi^{+}(\mathrm{O})$ & $\phi^{-}(\mathrm{)})$ & $\phi()$. \\
\hline Gamma & 0.48207 & 0.0 & 0.48207 \\
\hline Weibull & 0.44773 & 0.01073 & 0.437 \\
\hline Lognormal & 0.2208 & 0.14447 & 0.07633 \\
\hline Beta & 0.16133 & 0.20687 & -0.04553 \\
\hline Extreme Values & 0.084 & 0.35087 & -0.26687 \\
\hline Normal & 0.0 & 0.683 & -0.683 \\
\hline
\end{tabular}

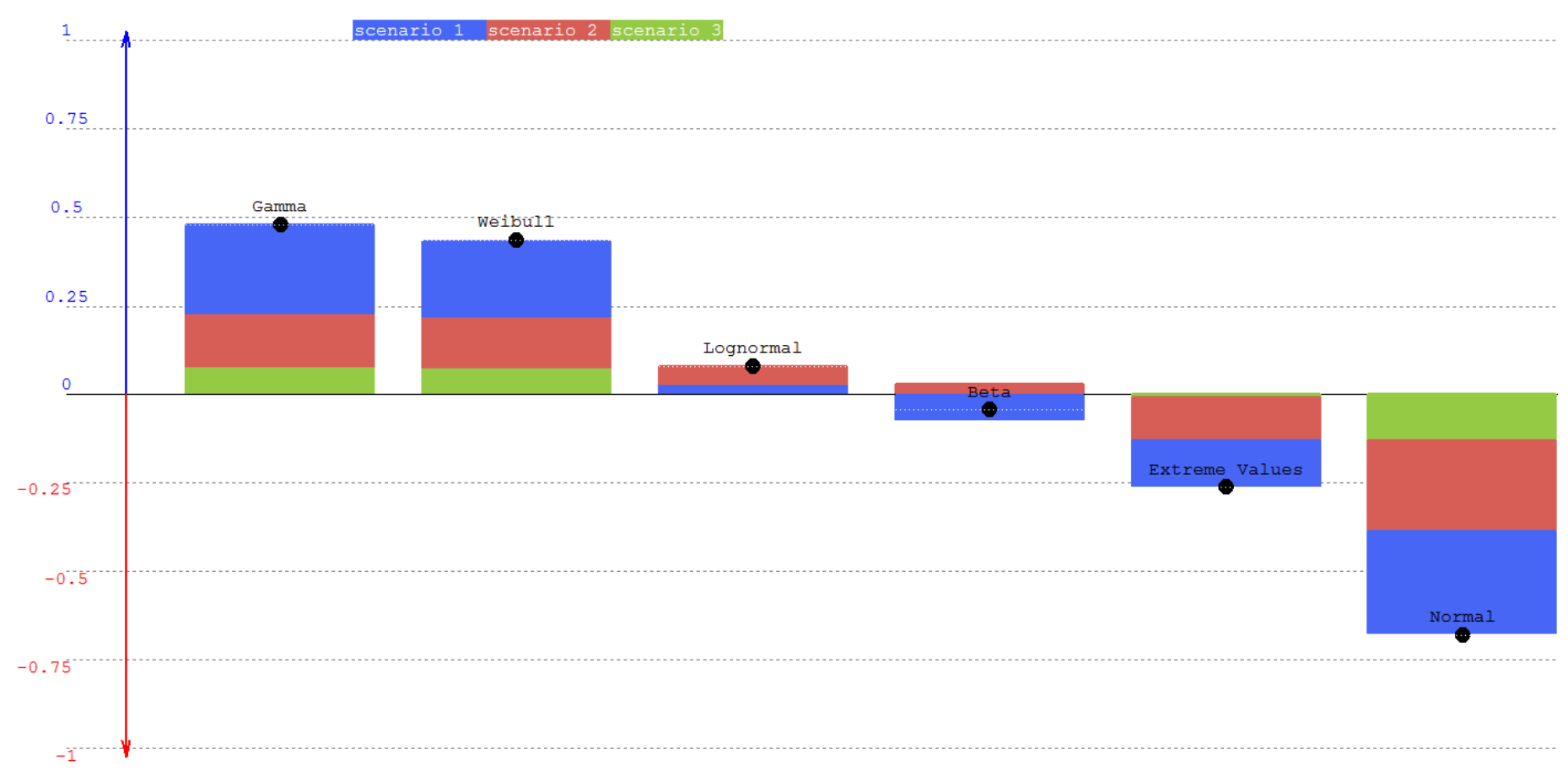

Figure 10: Composition of the unicriterion net flows for scenario 4.

From the Gaia plane (figure 11), it can be seen that all scenario (i.e. decision-makers) are very similar as their arrows are pointing in the same direction. Scenario 1 and 2 are the most dissimilar, which can be seen from the large angle of their projection. The group ranking is 
[Pre-print version], please cite as: Ishizaka A., Nemery P. Selecting the best statistical distribution with PROMETHEE and GAIA, Computers \& Industrial Engineering, doi: 10.1016/j.cie.2011.06.008, Advance Online Publication

deduced from the projections on the decision stick. Furthermore, the projection of the actions on a criterion (as in Figure 12) represents the ranking of a single decision-maker.

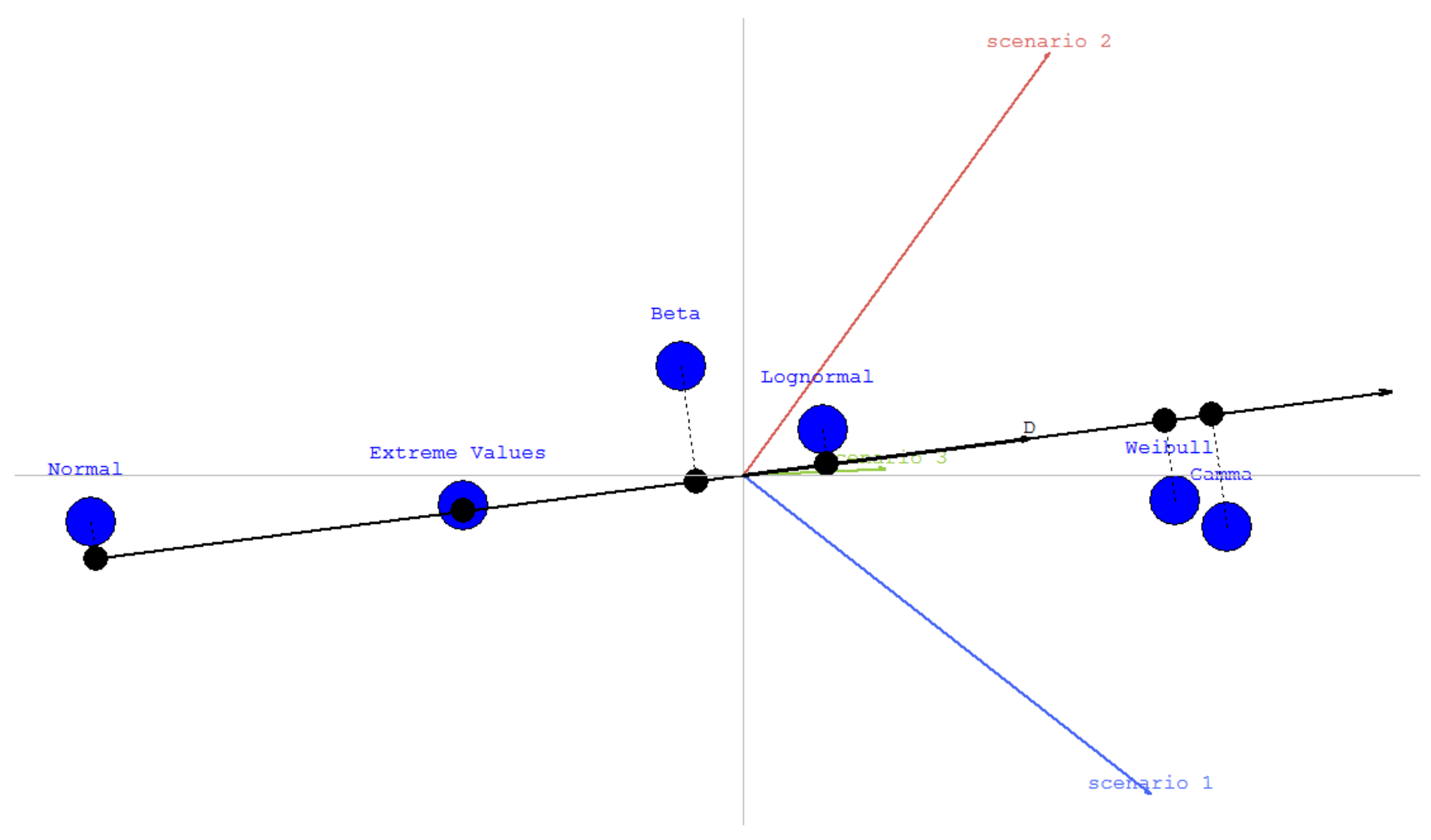

Figure 11: GAIA plane for the GDSS problem - scenario 4 with projections on the decision stick representing the group decisions.

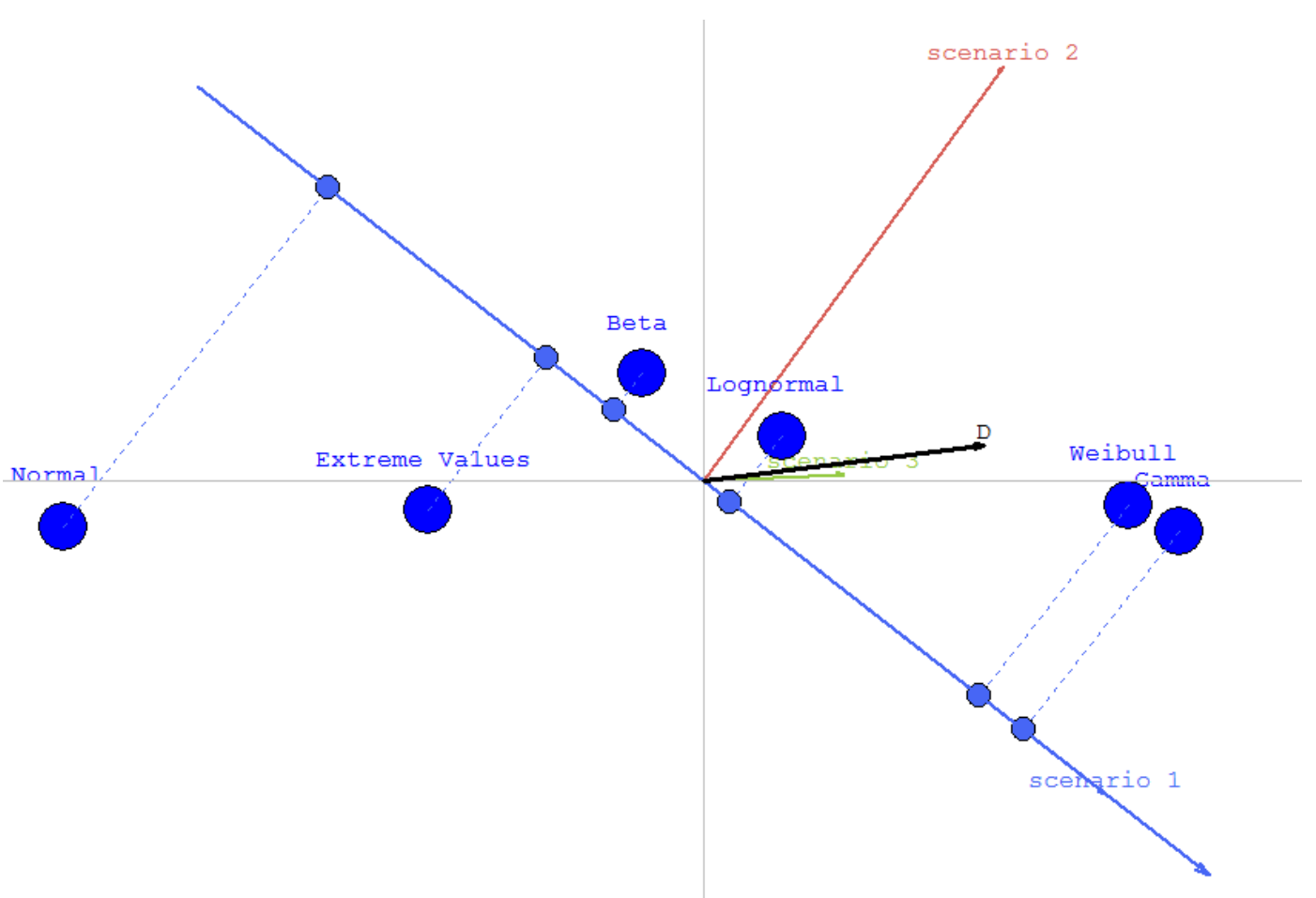

Figure 12: GAIA plane for the GDSS problem - scenario 4 with projection on criterion 1. 
[Pre-print version], please cite as: Ishizaka A., Nemery P. Selecting the best statistical distribution with PROMETHEE and GAIA, Computers \& Industrial Engineering, doi: 10.1016/j.cie.2011.06.008, Advance Online Publication

Table 8: Ranking of statistical distribution based on (Wang et al., 2004), (Ramanathan, 2005), (Tofallis, 2008), PROMETHEE II for scenario's 1,2,3 and 4.

\begin{tabular}{|l|c|c|c|c|c|c|}
\hline \multicolumn{1}{|c|}{ Method } & Beta & Gamma & Weibull & $\begin{array}{c}\text { Lognorma } \\
1\end{array}$ & Normal & $\begin{array}{c}\text { Extreme } \\
\text { Values }\end{array}$ \\
\hline Weighted sum & 4 & 1 & 2 & 3 & 6 & 5 \\
\hline DEA & 5 & 1 & 2 & 4 & 6 & 3 \\
\hline $\begin{array}{l}\text { Weighted } \\
\text { multiplication }\end{array}$ & 5 & 1 & 2 & 3 & 6 & 4 \\
\hline $\begin{array}{l}\text { PROMETHEE II - } \\
\text { Scenario 1 }\end{array}$ & 4 & 1 & 2 & 3 & 6 & 5 \\
\hline $\begin{array}{l}\text { PROMETHEE II - } \\
\text { Scenario 2 }\end{array}$ & 4 & 2 & 1 & 3 & 6 & 5 \\
\hline $\begin{array}{l}\text { PROMETHEE II - } \\
\text { Scenario 3 }\end{array}$ & 4 & 2 & 1 & 3 & 6 & 5 \\
\hline $\begin{array}{l}\text { PROMETHEE GDSS } \\
- \text { Scenario 4 }\end{array}$ & 4 & 1 & 2 & 3 & 6 & 5 \\
\hline
\end{tabular}

Table 9: Correlation coefficients for the rankings in table 8

\begin{tabular}{|l|l|l|c|c|c|c|c|}
\hline \multicolumn{1}{|c|}{ Method } & W. sum & DEA & $\begin{array}{c}\text { W. } \\
\text { multipl. }\end{array}$ & $\begin{array}{c}\text { Scenario } \\
1\end{array}$ & $\begin{array}{c}\text { Scenario } \\
2\end{array}$ & $\begin{array}{c}\text { Scenario } \\
3\end{array}$ & $\begin{array}{c}\text { Scenario } \\
4\end{array}$ \\
\hline Weighted sum & 1 & 0.829 & 0.943 & 1 & 0.943 & 0.886 & 1 \\
\hline DEA & 1 & 0.943 & 0.829 & 0.771 & 0.8860 & 0.829 \\
\hline $\begin{array}{l}\text { Weighted } \\
\text { multiplication }\end{array}$ & & & 1 & 0.943 & 0.886 & 0.943 & 0.943 \\
\hline $\begin{array}{l}\text { PROMETHEE II - } \\
\text { Scenario 1 }\end{array}$ & & & & 1 & 0.943 & 0.886 & 1 \\
\hline $\begin{array}{l}\text { PROMETHEE II - } \\
\text { Scenario 2 }\end{array}$ & & & & & 1 & 0.943 & 0.943 \\
\hline $\begin{array}{l}\text { PROMETHEE II - } \\
\text { Scenario 3 }\end{array}$ & & & & & & & 0.886 \\
\hline $\begin{array}{l}\text { PROMETHEE GDSS } \\
- \text { Scenario 4 }\end{array}$ & & & & & & & 1 \\
\hline
\end{tabular}

\section{Conclusions}

Three methods have been introduced to select a probability distribution to represent a set of data (Ramanathan, 2005; Tofallis, 2008; Wang et al., 2004). These three methods use predefined parameters without interaction with the decision-maker. However the correlation coefficients are high (table 9), their rankings is different (table 8). The ranking should depend on the preference system of the decision-maker, otherwise she/he will be dissatisfied. In this paper, we have introduced PROMETHEE and GAIA, which allow such modelling through interactions with the decision-maker. Four scenarios modelling different hypothetical decision-maker preferences have been discussed.

This constructive approach does not impose a set of parameters, like in a rational approach, but aims to capture the real preferences of the decision-maker. PROMETHEE does not 
[Pre-print version], please cite as: Ishizaka A., Nemery P. Selecting the best statistical distribution with PROMETHEE and GAIA, Computers \& Industrial Engineering, doi: 10.1016/j.cie.2011.06.008, Advance Online Publication

require any normalisation, which avoids the commensurability problem. The ranking of PROMETHEE I contains more information than other rankings because it can also highlight incomparable actions. GAIA with its visual interface allows a global view of the problem, which can lead to constructive discussions between the analyst and the decision-maker. For group decisions, PROMETHEE GDSS, an extension of PROMETHEE, can be applied. Unless an urgent decision is needed, where a constructive approach cannot be adopted, we would recommend using PROMETHEE and GAIA, which are supported by a user-friendly software system.

\section{References:}

Adler, N., Friedman, L. \& Sinuany-Stern, Z. (2002). Review of ranking methods in the data envelopment analysis context. European Journal of Operational Research, 140(2), 249-265.

Andreopoulou, Z., Kokkinakis, A. \& Koutroumanidis, T. (2009). Assessment and optimization of e-commerce websites of fish culture sector. Operational Research, 9(3), 293-309.

Araz, C. \& Ozkarahan, I. (2007). Supplier evaluation and management system for strategic sourcing based on a new multicriteria sorting procedure. International Journal of Production Economics, 106(2), 585-606.

Behzadian, M., Kazemzadeh, R.B., Albadvi, A. \& Aghdasi, M. (2010). PROMETHEE: A comprehensive literature review on methodologies and applications. European Journal of Operational Research, 200(1), 198-215.

Bell, D., Raiffa, H. \& Tversky, A. (1988). Decison making: descriptive normative and prescriptive interactions. In. Cambridge: Cambridge University Press.

Brans, J.-P. \& Mareschal, B. (1994). The PROMCALC \& GAIA decision support system for multicriteria decision aid. Decision Support Systems, 12(4-5), 297-310.

Brans, J.-P. \& Mareschal, B. (2005). PROMETHEE methods. In: J. Figueira, S. Greco \& M. Ehrgott, Multiple Criteria Decision Analysis:State of the Art Surveys. New York: Springer.

Brans, J. (1982). L'ingénierie de la décision: Elaboration d'instruments d'aide à la décision. In: R. Nadeaeu \& M. Landry, L'aide à la décision: Nature, Instruments et Perspectives d'Avenir (pp. 183-213). Québec: Presse de l'Université de Laval.

Brans, J. \& Vincke, P. (1985). A preference ranking organisation method. Management Science, 31(6), 647-656.

Castillo-Manzano, J., Castro-Nuño, M., Laxe, F., López-Valpuesta, L. \& Teresa ArévaloQuijada, M. (2009). Low-cost port competitiveness index: Implementation in the Spanish port system. Marine Policy, 33(4), 591-598.

Cornelissen, T., Jans, M., Stals, M., Kuppens, T., Thewys, T., Janssens, G., Pastijn, H., Yperman, J., Reggers, G., Schreurs, S. \& Carleer, R. (2009). Flash co-pyrolysis of biomass: The influence of biopolymers. Journal of Analytical and Applied Pyrolysis, 85(1-2), 87-97.

Doumpos, M. \& Zopounidis, C. (2010). A multicriteria decision support system for bank rating. Decision Support Systems, In Press, Corrected Proof, online advance publication, DOI: 10.1016/j.dss.2010.1007.1002.

Frenette, C., Beauregard, R., Abi-Zeid, I., Derome, D. \& Salenikovich, A. (2010). Multicriteria decision analysis applied to the design of light-frame wood wall assemblies. Journal of Building Performance Simulation, 3(1), 33 - 52. 
[Pre-print version], please cite as: Ishizaka A., Nemery P. Selecting the best statistical distribution with PROMETHEE and GAIA, Computers \& Industrial Engineering, doi: 10.1016/j.cie.2011.06.008, Advance Online Publication

Ghafghazi, S., Sowlati, T., Sokhansanj, S. \& Melin, S. (2010). A multicriteria approach to evaluate district heating system options. Applied Energy, 87(4), 1134-1140.

Ghazinoory, S., Divsalar, A. \& Soofi, A. (2009). A new definition and framework for the development of a national technology strategy: The case of nanotechnology for Iran. Technological Forecasting and Social Change, 76(6), 835-848.

Glover, F. \& Sueyoshi, T. (2009). Contributions of Professor William W. Cooper in Operations Research and Management Science. European Journal of Operational Research, 197(1), 1-16.

Halouani, N., Chabchoub, H. \& Martel, J. (2009). PROMETHEE-MD-2T method for project selection. European Journal of Operational Research, 195(3), 841-849.

Juan, Y.-K., Roper, K., Castro-Lacouture, D. \& Kim, J. (2010). Optimal decision making on urban renewal projects. Management Decision, 48(2), 207-224.

Kodikara, P., Perera, B. \& Kularathna, M. (2010). Stakeholder preference elicitation and modelling in multi-criteria decision analysis - A case study on urban water supply. European Journal of Operational Research, 206(1), 209-220.

Kwak, C. \& Kim, C. (2009). A multicriteria approach to timeout collaboration protocol. International Journal of Production Research, 47(22), 6417 - 6432.

Lanza, G. \& Ude, J. (2010). Multidimensional evaluation of value added networks. CIRP Annals - Manufacturing Technology, 59(1), 489-492.

Luk, J., Fernandes, H. \& Kumar, A. (2010). A conceptual framework for siting biorefineries in the Canadian Prairies. Biofuels, Bioproducts and Biorefining, 4(4), 408-422.

Macharis, C., Brans, J. \& Mareschal, B. (1998). The GDSS PROMETHEE procedure- A PROMETHEE-GAIA based procedure for group decision support. Journal of Decision Systems, 7, 283-307.

Mannino, M., Hong, S.N. \& Choi, I.J. (2008). Efficiency evaluation of data warehouse operations. Decision Support Systems, 44(4), 883-898.

Mareschal, B., De Smet, Y. \& Nemery, P. (2008). Rank Reversal in the PROMETHEE II Method : Some New Results. In: IEEE 2008 International Conference on Industrial Engineering and Engineering Management. Singapore.

Nemery, P. \& Lamboray, C. (2008). FlowSort: a flow-based sorting method with limiting or central profiles. TOP, 16(1), 90-113.

Ni, Y., Lai, Y., Brandes, S. \& Kokot, S. (2009). Multi-wavelength HPLC fingerprints from complex substances: An exploratory chemometrics study of the Cassia seed example. Analytica Chimica Acta, 647(2), 149-158.

Nikolic, D., Jovanovic, I., Mihajlovic, I. \& Zivkovic, Z. Multi-criteria ranking of copper concentrates according to their quality - An element of environmental management in the vicinity of copper - Smelting complex in Bor, Serbia. Journal of Environmental Management, 91(2), 509-515.

Nikolić, D., Milošević, N., Mihajlović, I., Živković, Ž., Tasić, V., Kovačević, R. \& Petrović, N. (2010). Multi-criteria Analysis of Air Pollution with SO\&lt;sub\&gt;2\&lt;/sub\&gt; and PM\&lt;sub\&gt;10\&lt;/sub\&gt; in Urban Area Around the Copper Smelter in Bor, Serbia. Water, Air, \&amp; Soil Pollution, 206(1), 369-383.

Oberschmidt, J., Geldermann, J., Ludwig, J. \& Schmehl, M. (2010). Modified PROMETHEE approach for assessing energy technologies. International Journal of Energy Sector Management, 4(2), 183-212.

Ramanathan, R. (2005). Selecting the best statistical distribution - a comment and a suggestion on multi-criterion evaluation. Computers \& Industrial Engineering, 49(4), 625-628. 
[Pre-print version], please cite as: Ishizaka A., Nemery P. Selecting the best statistical distribution with PROMETHEE and GAIA, Computers \& Industrial Engineering, doi: 10.1016/j.cie.2011.06.008, Advance Online Publication

Ramzan, N., Naveed, S., Feroze, N. \& Witt, W. (2009). Multicriteria decision analysis for safety and economic achievement using PROMETHEE: A case study. Process Safety Progress, 28(1), 68-83.

Roy, B. (1996). Multicriteria methodology for decision aiding. Dordrecht: Kluwer Academic Publisher.

Roy, B. (2009). Two conceptions of decision aiding. Newsletter fo the European Working Group "Multicriteria Aid for Decisions", 19(3), 1-3.

Safaei Mohamadabadi, H., Tichkowsky, G. \& Kumar, A. (2009). Development of a multicriteria assessment model for ranking of renewable and non-renewable transportation fuel vehicles. Energy, 34(1), 112-125.

Saidi Mehrabad, M. \& Anvari, M. (2010). Provident decision making by considering dynamic and fuzzy environment for FMS evaluation. International Journal of Production Research, 48(15), 4555 - 4584.

Semaan, N. \& Zayed, T. (2010). A stochastic diagnostic model for subway stations. Tunnelling and Underground Space Technology, 25(1), 32-41.

Serrano-Cinca, C., Fuertes-Callén, Y. \& Mar-Molinero, C. (2005). Measuring DEA efficiency in Internet companies. Decision Support Systems, 38(4), 557-573.

Silva, V., Morais, D. \& Almeida, A. (2010). A Multicriteria Group Decision Model to Support Watershed Committees in Brazil. Water Resources Management, 1-17.

Soltanmohammadi, H., Osanloo, M. \& Aghajani Bazzazi, A. (2009). Deriving preference order of post-mining land-uses through MLSA framework: application of an outranking technique. Environmental Geology, 58(4), 877-888.

Sueyoshi, T. \& Goto, M. (2009a). Can R\&D expenditure avoid corporate bankruptcy? Comparison between Japanese machinery and electric equipment industries using DEA-discriminant analysis. European Journal of Operational Research, 196(1), 289311.

Sueyoshi, T. \& Goto, M. (2009b). DEA-DA for bankruptcy-based performance assessment: Misclassification analysis of Japanese construction industry. European Journal of Operational Research, 199(2), 576-594.

Sueyoshi, T. \& Sekitani, K. (2009). An occurrence of multiple projections in DEA-based measurement of technical efficiency: Theoretical comparison among DEA models from desirable properties. European Journal of Operational Research, 196(2), 764794.

Tofallis, C. (2008). Selecting the best statistical distribution using multiple criteria. Computers \& Industrial Engineering, 54(3), 690-694.

Triantaphyllou, E. (2001). Two new cases of rank reversals when the AHP and some of its additive variants are used that do not occur with the Multiplicative AHP. Journal of Multi-Criteria Decision Analysis, 10(1), 11-25.

Tsoukiàs, A. (2008). From decision theory to decision aiding methodology. European Journal of Operational Research, 187(1), 138-161.

Tuzkaya, G., Gülsün, B., Kahraman, C. \& Özgen, D. (2010). An integrated fuzzy multicriteria decision making methodology for material handling equipment selection problem and an application. Expert Systems with Applications, 37(4), 2853-2863.

Varian, H. (1999). Intermediate Microeconomics. New York: W. W. Norton \& Company.

Venkata Rao, R. \& Patel, B. (2010). Decision making in the manufacturing environment using an improved PROMETHEE method. International Journal of Production Research, 48(16), 4665 - 4682.

Vincke, P. (1992). Multicriteria Decision-Aid. Chichester: John Willey \& Sons.

Wang, Y. \& Luo, Y. (2009). On Rank Reversal in Decision Analysis. Mathematical and Computer Modelling, 49(5-6), 1221-1229. 
[Pre-print version], please cite as: Ishizaka A., Nemery P. Selecting the best statistical distribution with PROMETHEE and GAIA, Computers \& Industrial Engineering, doi: 10.1016/j.cie.2011.06.008, Advance Online Publication

Wang, Y., Yam, R. \& Zuo, M. (2004). A multi-criterion evaluation approach to selection of the best statistical distribution. Computers \& Industrial Engineering, 47(2-3), 165180.

Zhang, K., Achari, G. \& Pei, Y. (2010). Incorporating linguistic, probabilistic, and possibilistic information in a risk-based approach for ranking contaminated sites. Integrated Environmental Assessment and Management, 6(4), 711-724.

Zhang, K., Kluck, C. \& Achari, G. (2009). A Comparative Approach for Ranking Contaminated Sites Based on the Risk Assessment Paradigm Using Fuzzy PROMETHEE. Environmental Management, 44(5), 952-967.

Zhu, Z., Xu, L., Chen, G. \& Li, Y. (2010). Optimization on tribological properties of aramid fibre and $\mathrm{CaSO} 4$ whisker reinforced non-metallic friction material with analytic hierarchy process and preference ranking organization method for enrichment evaluations. Materials \& Design, 31(1), 551-555. 